\title{
Antonia ovata Pohl var. excelsa Paula ex Paula (Loganiaceae)
}

\author{
José Elias de Paula $\left({ }^{*}\right)$
}

\begin{abstract}
Resumo
Neste trabalho são considerados os aspectos morfológicos externo e palinológico de três variedades de Antonia ovata Pohl, ocorrentes na floresta da região do rio Jari (Estado do Pará) e nos cerrados da Amazônia e do Planalto Central brasileiro.
\end{abstract}

Em trabalino anterior (Paula, 1972: Acta Amazonica 2 (2):59) deixamos de colocar a diagnose latina da variedade em apreço, razão pela qual apresentamos nesta comunicação.

\section{DIAGNOSE DA NOVA VARIEDADE}

Antonia ovata Pohl var. excelsa Paula ex Paula Antonia ovata Pohl var. excelsa Paula, Acta Amazo. nica $2(2): 59$, fotos $1,6,13,16,17,20$ e 21 , fig. 1 a-d e fig. 2 d. 1972.

Arbor circa $30 \mathrm{~m}$ alta et $1 \mathrm{~m}$ diametro; rami pilosi; folia subglabra, ovata vel ovato-elliptica, ad basin cordata vel attenuata; nervatio secundaria camptodroma, raro brochidodroma prope apicem; pedunculus inflorescentiae pilosus; pollinis grana prolato-sphaeroidea etiam prolata aequatorialiter visa; subcircularia polariter visa, diametro polaris 16-19 micra.

Árvore com cerca de $30 \mathrm{~m}$ de altura e $1 \mathrm{~m}$ de diâmetro; ramos piiosos; folhas quase gla bras, ovadas ou ovado-elípticas, cordadas ou atenuadas na base; nervação secundária camptódiroma, raramente broquidódroma próximo do ápice; pedúnculo da inflorescência piloso; grãos de polem subreticulados, prolato-esferoidais em vista equatorial, ocorrendo também grãos de polem prolatos; subcirculares em vista polar; diâmetro polar entre 16 e $19 \mu$; a 3 colpi, com margem; os subcircular, com tendência à "lolongate". Madeira leve de cor bege; alburno indistinto do cerne; camadas de crescimento pouco visíveis; casca fina, lisa.

HABITAT: mata alta de terra firme, rio Jari, Estado do Para, Brasil.

TIPO: E. Oliveira 4806, localidade (Holótipo, IAN),

PARÁrIPOS: Localidade, E. Oliveira 4817 (IAN); localidade, N. T. Silva 2864 (IAN); localidade, J. M. Pires 511 (IAN).

Com a descrição desse novo taxon, o número de variedades de Antonia ovata eleva-se para três: Antonia ovata Pohl var. ovata, A. ovata Pohl var. pilosa (Hook.) Progel e A. ovata Pohl var. excelsa Paula ex Paula.

Antonia ovata Pohi var. excelsa constitui vicariância com as outras variedades: ovata e pilosa. Estas ocorrem nos cerrados da Amazônia e do Planalto Central Brasileiro.

As madeiras das variedades ovata e pilosa apresentam fluorescência azul celeste quando iluminadas por luz ultra-violeta de ondas lon. gas.

\section{CHAVE PARA AS VARIEDADES}

A. Arbusto ou árvore fina de até $8 \mathrm{~cm}$ de diâmetro e 4 a $10 \mathrm{~m}$ de altura, do cerrado; madeira leve de cor cinza-claro.

a. Folha e pedúnculo da inflorescência glabros, às vezes ocorrendo pelos apenas no nó foliar e ao longo das nervuras secundárias.

........ var. ovata

aa. Folha, ramo e pedúnculo da inflorescência densamente pilosos. .......... var. pilosa.

B. Árvore de ate $30 \mathrm{~m}$ de altura por até $1 \mathrm{~m}$ de diâmetro, da mata; madeira de cor bege ......... var. excelsa

(") - Universidade de Brasília. 


\section{MATERIAL ADICIONAL EXAMINADO}

Antonia ovata Pohl var. pilosa (Hook) Progel ( $=$ A. pubescens Borg.): Fróes 30074 (UB).

Antonia ovata Pohl var. ovata $(=A$. ovata Pohl var. glabra Progel): J. Elias de Paula 516 (UB); J. Elias 517 (UB); Hunt et Ramos 5741 (UB); Prance et alii 5920 (UB); M. Magalhães 19499 (UB); A. P. Duarte et A. Maitos 603 (UB); Philcox et Onishi 4907 (UB).

\section{A G R A D E C I M E N T O S}

Ao Dr. Jorge Fontella, do Jardim Botânico do Rio de Janeiro; Dr. Robert Goodland, do New York Botanical Garden; Dr. Ezechias P. Henringer e Dr. George Eiten, da Universidade de Brasília, gratos pela colaboração que nos foi prestada para a execução deste trabaIho.

\section{SUMMARY}

In this paper the author studies extern morphological and palinological aspects of the three varieties of the Antonia ovata Pohl: var. ovata, var. pilosa and var. excelsa.

The var. excelsa from the woods of region of Jari river (Amazonia), and the var. ovata and var. pilosa from "cerrado" of Amazonia, and Central Brazil.

Pollen grains of the two varieties excelsa and ovata present polymorphism.

The identification of the three varieties is based on the following characteristics: presence or lack of hairs on the leaves and branches; height and diameter of the specimens; and, finally, the habitat.

\section{BIBLIOGRAFIA CITADA}

Paula, José Elias de

1972 - Estudo anatômico e palinológico de Antonia ovata Pohl. (Loganiaceae). Acta Amazonica, Manaus, 2(2):55-69, fotos 1-19, figs. 1-3. 